\title{
Probiotics in Gastrointestinal Diseases: All that Glitters Is Not Gold
}

\author{
Debora Compare Costantino Sgamato Olga Maria Nardone Alba Rocco \\ Pietro Coccoli Carmen Laurenza Gerardo Nardone \\ Department of Clinical Medicine and Surgery, Gastroenterology, University Federico II of Naples, Naples, Italy
}

\begin{abstract}
Keywords
Helicobacter pylori infection · Irritable bowel syndrome · Inflammatory bowel disease · Gut microbiota
\end{abstract}

\begin{abstract}
Background: Multiple lines of evidence now support the notion that gut microbiota can contribute to digestive and extra-digestive diseases. The emergence of these observations enabled to postulate a bacteria-centric paradigm to rethink the treatment of many diseases. The goal of therapy should not be to eradicate the flora but to modify it in a way that leads to symptomatic improvement; thus, the interest in the use of probiotics to modulate microbiota composition has increased worldwide in both community and healthcare settings. Summary: The results of published studies are conflicting for most probiotic strains and formulations, and clinicians and consumers need a better understanding of probiotic risks and benefits. Currently, clear guidelines on when to use probiotics and the most effective probiotic for different gastrointestinal conditions are still lacking. Here, we reviewed the studies on the use of probiotics in some diseases of relevant interest to gastroenterologists, such as Helicobacter pylori infection, irritable bowel syndrome, and inflammatory bowel disease. Key Message: Although the evidence is relevant and promising for probiotics in general, and for specific strains and combinations of strains, it is not yet sufficient to draw unequivocal conclusions and clear recommendations.

(c) 2021 S. Karger AG, Basel
\end{abstract}

\section{Introduction}

Probiotics, which translates from Greek as "for life," are defined by the Food and Agricultural Organization and the World Health Organization as "live microorganisms which, when administered in adequate amounts, confer a health benefit on the host" [1]. A considerable amount of data based on human observational studies and animal model systems suggests a pathogenetic implication of the gut microbiota in a broad range of chronic human conditions, including cancer and diseases with inflammatory, metabolic, cardiovascular, autoimmune, neurologic, and psychiatric components [2-4]. However, since the gastrointestinal tract harbours most of the microbes in the human body, housing several trillion microbial cells, gut flora changes have emerged as a leading mechanism in some gastrointestinal diseases $[5,6]$.

As the research field developed, it has enabled to postulate a bacteria-centric paradigm to rethink the treatment of gastrointestinal diseases [7]. However, therapy goal should not be to eradicating the flora but modifying it in a way that leads to symptomatic improvement; thus, probiotics look like a fascinating approach. Probiotic microorganisms act through various mechanisms, including modulation of immune function, production of organic acids and antimicrobial compounds, interaction with resident microbiota, interfacing with the host, improving gut barrier integrity, and enzyme formation $[8$, 9]. $\begin{array}{ll}\text { karger@karger.com } & \text { (c) 2021 S. Karger AG, Basel } \\ \text { www.karger.com/ddi } & \end{array}$

Karger
Correspondence to:

Debora Compare, debora.compare@ unina.it

Gerardo Nardone, nardone@ unina.it 


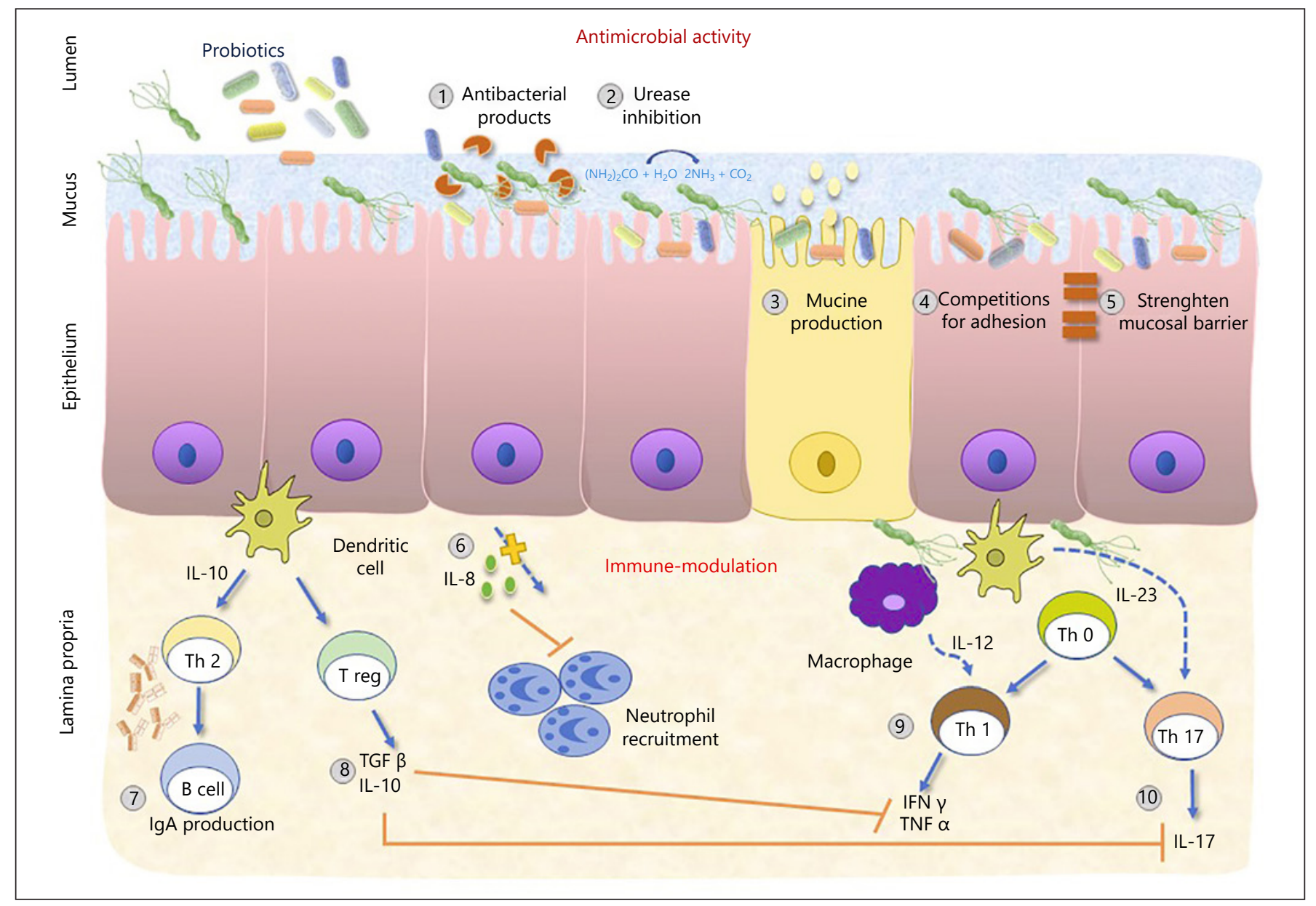

Fig. 1. Antimicrobial and immunomodulatory mechanisms through which probiotics may contribute to fighting $H$. pylori infection. The antimicrobial activity is carried out by secreting antibacterial products (1), inhibiting the activity of the urease enzyme (2), increasing mucus production (3), reducing $H$. pylori ability to adhere to gastric epithelial cells (4), and strengthening

All these effects would be mediated through direct interaction with commensal microbiota or be non-microbiotamediated and likely differ by species. Some probiotics may trigger natural killer cell activity and antibody secretion, and others increase the release of anti-inflammatory cytokines or the production of organic acids that lower luminal $\mathrm{pH}$ and inhibit the growth of pathogen bacteria [10]. Furthermore, probiotic effectiveness can be species-, dose-, and disease-specific, and the duration of therapy depends on the clinical indication [11]. Therefore, to obtain a specific response, a particular strain, dose, and duration must be used.

A Cochrane review found that a dosage of 5 billion colony-forming units or greater per day was significantly more effective than a lower dosage [8]. Currently, clear the mucosal barrier (5). The modulation of the immune and inflammatory responses of the host is carried out by inhibiting IL-8 production (6), increasing IgA production (7), stimulating antiinflammatory $\mathrm{T}$ reg response (8), and inhibiting pro-inflammatory Th 1 and Th 17 response $(9,10)$.

guidelines on when to use probiotics and the most effective probiotic for different gastrointestinal conditions are lacking. The objective of this article is to review the evidence for the use of probiotics in some diseases of relevant interest to gastroenterologists, such as Helicobacter pylori $(H$. pylori) infection, irritable bowel syndrome (IBS), and inflammatory bowel disease (IBD).

\section{Helicobacter Pylori Infection}

Although the epidemiology of $H$. pylori has been changing over the last decades, with a decline of the prevalence of the infection in most countries, more than half 
the world's population is infected [12]. H. pylori is the leading cause of chronic gastritis and peptic ulcer disease and plays a pathogenic role in the development of gastric adenocarcinoma and gastric mucosa-associated lymphoid tissue lymphoma [13]. Moreover, this bacterium has been associated with some extra-gastric diseases, including iron- or vitamin B12-deficient anaemia or primary idiopathic thrombocytopenia [13].Many of these diseases (such as ulcer disease and mucosal-associated lymphoid tissue lymphoma) have become curable, and others (gastric cancer) might be preventable by eradicating $H$. pylori infection [13]. Thus, international medical guidelines strongly recommend eradication of $H$. pylori with multiantibiotic therapy [14-17].

Nevertheless, owing to its wide use and the increasing use of antibiotics in general, $H$. pylori treatment regimens are burdened by a high failure rate. While increasing the dose and course of antibiotics can improve the eradication rates, the increased antibiotics-related side effects can impair therapy adherence and further hamper the eradication success rate [18]. These challenges have raised the need for new alternative approaches to treating $H$. $p y$ lori infections, among which probiotics represent the most promising option.

It is well known that most probiotics can colonise the human gut; however, certain species, such as Lactobacillus, Bifidobacterium, and Saccharomyces spp., can also colonise the human stomach, where directly or indirectly they can antagonise $H$. pylori [19-21]. The mechanisms through which probiotics can antagonise $H$. pylori include inhibition of $H$. pylori growth by secreting antibacterial substances or by hindering the activity of urease enzyme and reduction of $H$. pylori infectivity by reducing its ability to adhere to gastric epithelial cells, by strengthening mucosal barrier, and by regulating immune and inflammatory responses of the host (Fig. 1) [22-25].

It has been reported that the administration of probiotics alone can reduce the gastric bacterial load of $H$. $p y$ lori, whereas using probiotics in combination with antibiotics can improve the eradication rate $[26,27]$. Moreover, because the eradication of $H$. pylori is associated with widespread changes in gut microbial ecology and structure, probiotic supplementation, by modulating gut microbiota and host immune responses, could relieve antibiotic-related gastrointestinal symptoms, thus contributing to ameliorate adherence and eradication rates [23].

A few studies addressed a direct role of probiotic alone in eradicating $H$. pylori. A meta-analysis including eleven studies with a total of 517 patients published in 2018 investigated the effects of probiotic monotherapy on $H$. $p y$ - lori eradication. The authors found that probiotics eradicated $H$. pylori in $14 \%$ of cases with an OR of 7.91 in favour of probiotics (95\% confidence interval (CI) 2.9721.05, $p<0.001)$. Lactobacilli, Saccharomyces boulardii, and multistrain combinations eradicated the bacterium with a rate of 16,12 , and $14 \%$, respectively. Although with an unsatisfactory rate, probiotics were significantly more effective than placebo, without significant difference in adverse events compared to placebo, thus representing an alternative strategy in selected cases [28]. Nevertheless, most studies aimed to evaluate the efficacy of probiotic supplementation during standard antibiotic therapy on $H$. pylori infection eradication rate.

A meta-analysis of 13 randomised controlled trials involving a total of 2,306 patients showed that the pooled relative risk (RR) of eradication was significantly higher in the probiotic supplementation group than in the control group (RR 1.15, 95\% CI: $1.10 \pm 1.20, p<0.00001$ ). The incidence of total antibiotic-related side effects was lower in the probiotic supplementation group than in the control group, and the pooled RR was 0.71 (95\% CI: $0.54 \pm$ $0.94, p=0.02)$. Subgroup analysis showed that eradication rates were significantly improved in both adults and children, that no regional differences between Europe and Asia were present, and that therapy regimens and treatment durations did not affect the eradication rates. The incidence of antibiotic-related side effects was significantly reduced in all groups, except for the quadruple therapy subgroup. Supplementation with Lactobacillus alone or multistrain probiotics was effective in improving $H$. pylori eradication rates. However, supplementation with Lactobacillus alone did not significantly decrease the overall incidence of side effects [29].

Regarding the Lactobacillus strains, a further metaanalysis showed that the pooled RR was 1.33 (95\% CI $1.10-1.62$ ) in the Lactobacillus casei group, 1.18 (95\% CI $1.03-1.34$ ) in the Lactobacillus reuteri group, and 1.02 (95\% CI 0.87-1.21) in the Lactobacillus GG group. As for the total side effects, Lactobacillus supplementation significantly reduced the incidence of taste disturbance $(\mathrm{RR}=0.36,95 \%$ CI $0.17-0.74, p=0.005)$ [30].

More recently, a meta-analysis of forty studies, including 5,792 patients, confirmed these data. Notably, probiotic supplementation improved the eradication rate by approximately $10 \%$ relative to the control group (OR, 1.94, 95\% CI: $1.70-2.22, p<0.00001)$. The incidence of total side effects (OR, $0.56,95 \%$ CI: $0.45-0.70, p<0.00001$ ) and individual symptoms (e.g., diarrhoea, vomiting and nausea, constipation, epigastric pain, and taste disturbance) also decreased significantly with probiotic supple- 
Table 1. Guidelines on the role of probiotics in $H$. pylori infection

\begin{tabular}{|c|c|c|c|c|}
\hline Source & Year & Recommendations & $\begin{array}{l}\text { Strength of } \\
\text { recommendation }\end{array}$ & $\begin{array}{l}\text { Quality of } \\
\text { evidence }\end{array}$ \\
\hline $\begin{array}{l}\text { The Toronto Consensus for the } \\
\text { treatment of H. pylori infection in } \\
\text { adults [16] }\end{array}$ & 2016 & $\begin{array}{l}\text { In patients with } H \text {. pylori infection, we recommend against routinely } \\
\text { adding probiotics to eradication therapy for the purpose of reducing } \\
\text { adverse events }\end{array}$ & Strong & Very low \\
\hline \multirow[t]{2}{*}{$\begin{array}{l}\text { Management of } H \text {. pylori } \\
\text { infection - the Maastricht V/ } \\
\text { Florence Consensus Report [14] }\end{array}$} & 2017 & $\begin{array}{l}\text { Only certain probiotics have been shown to be effective in reducing } \\
\text { gastrointestinal side effects caused by } H \text {. pylori eradication therapies. } \\
\text { Specific strains should be chosen only upon the basis of a demonstrated } \\
\text { clinical efficacy }\end{array}$ & Strong & Moderate \\
\hline & & Certain probiotics may have a beneficial effect on $H$. pylori eradication & Weak & Very low \\
\hline $\begin{array}{l}\text { ACG clinical guideline: Treatment } \\
\text { of Helicobacter pylori infection [15] }\end{array}$ & 2017 & $\begin{array}{l}\text { Although probiotic therapy for } H \text {. pylori infection seems promising, } \\
\text { many important questions remain, including the optimal dose, the time } \\
\text { of dosing (before, during, or after eradication therapy), and the duration } \\
\text { of therapy }\end{array}$ & N/A & N/A \\
\hline
\end{tabular}

ACG, American College of Gastroenterology.

mentation. No other differences in side effects were observed between the experimental and control groups. Moreover, a longer duration ( $>10$ days) of probiotic treatment had positive effects on both the H. pylori eradication rate and incidence of overall side effects [31].

Overall, although the available studies showed some efficacy of probiotics in combination with antibiotics on the $H$. pylori eradication rate, the heterogeneity of these studies in terms of probiotics used (bacterial or fungal species, dose, and duration), type (amoxicillin, clarithromycin, metronidazole, etc.) and duration $(7,10$, or 14 days) of antibiotics, and treatment regimen used (triple, sequential, hybrid, bismuth-, and non-bismuth-based quadruple therapy) makes it challenging to interpret the results and reach a common conclusion. Thus far, current guidelines do not yet provide recommendations on the routinely use of probiotics in $H$. pylori eradication treatment regimens in clinical practice, but at most they suggest them as a promising future strategy or even discourage their routine administration to reduce side effects and improve the efficacy (Table 1) [16-19].

\section{Irritable Bowel Syndrome}

IBS is the most common functional gastrointestinal disorder, particularly in females and younger individuals $(<50$ year), with a worldwide prevalence ranging from 7 to $21 \%$ [32]. IBS is characterised by abdominal pain related to defecation and change in bowel frequency and stool consistency in the absence of structural and biochemical abnormalities. According to Rome IV criteria and the predominant disorder in bowel habits, IBS has been classified into 4 main subtypes [33]. Treatment should be based on the symptom type and severity and is generally centred on lifestyle modification (physical exercise and stress reduction), dietary adjustment (soluble fibre supplementation or low-FODMAP diet), and medical therapies (laxatives, antidiarrhoeals, and spasmolytics) [34].

The pathophysiology of IBS is complex and not fully understood. Likely, several factors, including altered brain-gut interactions, changes of the microbiome, visceral or central hypersensitivity, abnormal gastrointestinal motility, and psychosocial factors, are involved in disease expression [35]. Until now, no validated treatment algorithm exists; thus, treating IBS patients is still a challenge. The concept that alterations in the gut microbiota might be relevant in the pathogenesis of IBS arose from the observation that up to $31 \%$ of patients develop IBS after an infection (postinfectious IBS) [36]. Besides, many studies have demonstrated the efficacy and durable improvement of IBS symptoms after treatment with antibiotics, especially the non-absorbable antibiotic rifaximin [37-39].

Probiotics, by modulating the composition of gut microbiota, stimulating the immune system, and enhancing intestinal permeability have been proposed as a therapeutic approach for IBS [40]. The most widely used probiotic bacteria strains are Bifidobacterium, Enterococcus, Lactobacillus, Saccharomyces boulardii, and Escherichia coli Nissle 1917 [41].

The first published randomised controlled trial exploring the possible beneficial use of probiotics in IBS was 
conducted in France in 1983. Patients who received Saccharomyces boulardii experienced significant improvement in stool consistency and the daily number of stools compared to placebo $(p<0.05)$ [42]. Since then, a considerable amount of data on the use of probiotics for IBS treatment has been produced. However, the significant heterogeneity in study design (size of the study, duration of the treatment, outcome analysed, and type, dose, and strains of probiotics used), resulted in controversial conclusions. One of the first attempts to systematically review the RCTs evaluating the efficacy, safety, and tolerability of probiotics in IBS treatment was made by Brenner et al. [43] in 2009. The authors found that only Bifidobacterium infantis $(35,624)$ was efficacious in improving IBS symptoms scores compared with placebo $(p<0.05)$. More recently, Ford et al. [44], by analysing 53 RCTs involving 5,545 patients, demonstrated that when using a dichotomous outcome (persistence of symptoms), probiotics were statistically superior to placebo (RR of IBS, not improving $=0.81 ; 95 \%$ CI $0.74-0.88)$. These findings were confirmed by a subsequent meta-analysis of 35 RCTs involving 3,452 patients performed by Niu et al. [45]. Lactobacillaceae and Bifidobacteriaceae were the most frequent families of probiotics analysed in the included studies. Patients using probiotics had a lower incidence of the persistence of symptoms (RR $0.79,95 \%$ CI 0.70 $0.89, p<0.0001)$ and positive effects on symptomatic scores. However, a higher incidence of any adverse event (RR 1.21; 95\% CI 1.02-1.44) was noted. Overall, probiotics were deemed superior to placebo regarding global symptoms, albeit with a weak recommendation and low strength of evidence [45]. In 2020, a technical review performed by the American Gastroenterology Association (AGA) has compiled evidence from 76 well-conducted randomised placebo-controlled clinical trials that used 44 different probiotic strains or combinations of strains to determine whether the use of probiotics is justified in IBS patients [46]. Only 2 formulations (Saccharomyces boulardii and an 8-strain combination of Lactobacillus paracase $i$ ) had $>1$ trial measure the same outcome, thus facilitating combined case analyses. The 3 studies testing Saccharomyces boulardii in 232 patients did not evidence significant difference in the abdominal pain score with respect to placebo (standardised $\mathrm{MD}, 0.26 ; 95 \% \mathrm{CI},-0.09$ to 0.61 ). Two trials assessing an 8 -strain combination of Lactobacillus paracasei in 73 patients with IBS demonstrated a decrease in the abdominal pain score using the Visual Analogue Scale (mean decrease, -3.78; 95\% CI, -4.93 to -2.62 ). On the contrary, the 6-strain combination of Bifidobacterium longum subsp longum, Bifidobac-

Probiotics and GI Diseases terium bifidum, Bifidobacterium animalis subsp lactis, Lactobacillus acidophilus, Lactobacillus rhamnosus, and Saccharomyces salivarius subsp thermophilus was found to be inferior to placebo for global relief of symptoms in adults with IBS. Globally, the overall quality of evidence was very low and did not allow to draw definitive conclusions about the efficacy of probiotics in IBS management.

The large number of published RCTs on probiotics underlines the continuing interest in manipulating the gut microbiota as a potential therapy for IBS. Some of the latest RCTs that had investigated the role of probiotics in IBS are given below. A randomised, placebo-controlled clinical trial by Andresen et al. [47] has assessed the efficacy of non-viable (heat-inactivated) Bifidobacterium bifidum HI-MIMBb75 in a real-life setting of IBS patients. Compared with placebo, Bifidobacterium bifidum HI$M I M B b 75$ was associated with significant improvement in health-related quality of life, IBS symptom scores, and global symptom relief. Non-viable bacteria might have advantages over some living probiotics because their use is associated with better standardisation, greater stability, and improved safety [48]. Martoni et al [49] in a unique 3-arm placebo-controlled trial simultaneously investigated the clinical efficacy of 2 probiotic strains (Lactobacillus acidophilus DDS-1 and Bifidobacterium lactis UABla-12) on abdominal pain severity and other symptoms in 330 IBS patients. Participants in both probiotic groups showed a significant improvement in abdominal pain, symptom severity scores, and a corresponding normalisation of bowel habits compared to placebo [49]. Gayathri et al. [50] demonstrated that the addition of oral administration Saccharomyces cerevisiae CNCM I-3856 to standard therapy in patients with IBS was associated with a significant improvement in abdominal pain and stool consistency due to its analgesic and anti-inflammatory activity compared to placebo [50]. Madempudi et al. [51] investigated the efficacy of Bifidobacterium coagulans Unique IS2 in the management of IBS symptoms in 136 patients. There was a significant reduction of abdominal discomfort/pain intensity and an increase in complete spontaneous bowel movements in the probiotic group [51].

Interpreting the existing literature is problematic because of small studies, the multiple types and strains of probiotics, the inconsistent benefits on individual symptoms, and the lack of rigorous trials based on definite endpoints. Thus, although numerous randomised controlled trials explored the role of probiotics in the management of IBS, with some trials showing positive results, recommendations on which combination, species, or strain is effective are still lacking. 
Table 2. Guidelines on the role of probiotics in IBS

\begin{tabular}{|c|c|c|c|c|}
\hline Source & Year & Recommendations & $\begin{array}{l}\text { Strength of } \\
\text { recommendation }\end{array}$ & $\begin{array}{l}\text { Quality of } \\
\text { evidence }\end{array}$ \\
\hline ACG monograph on management of IBS [34] & 2018 & $\begin{array}{l}\text { We suggest probiotics taken as a group to improve global } \\
\text { symptoms, as well as bloating and flatulence in IBS patients }\end{array}$ & Weak & Low \\
\hline $\begin{array}{l}\text { AGA clinical practice guidelines on the } \\
\text { role of probiotics in the management of } \\
\text { gastrointestinal disorders [52] }\end{array}$ & 2020 & $\begin{array}{l}\text { In symptomatic children and adults with IBS, we } \\
\text { recommend the use of probiotics only in the context of a } \\
\text { clinical trial }\end{array}$ & $\begin{array}{l}\text { No } \\
\text { recommendations }\end{array}$ & $\begin{array}{l}\text { Knowledge } \\
\text { gap }\end{array}$ \\
\hline $\begin{array}{l}\text { ACG clinical guideline: Management of IBS } \\
\text { [53] }\end{array}$ & 2021 & $\begin{array}{l}\text { We suggest against probiotics for the treatment of global } \\
\text { IBS symptoms }\end{array}$ & Conditional & Very low \\
\hline
\end{tabular}

IBS, irritable bowel syndrome; ACG, American College of Gastroenterology; AGA, American Gastroenterology Association.

Currently, AGA guidelines recommend the use of probiotics in IBS only in the context of a clinical trial [52], while the American College of Gastroenterology guidelines on management of IBS suggest against probiotics for the treatment of global IBS. Symptoms are presented in Table 2 [53]. Probiotics seem to be a promising treatment modality due to their diverse modes of action, which might be used to target the multifactorial aetiology of IBS, but more well-powered randomised controlled trials are warranted.

\section{Inflammatory Bowel Disease}

IBD, including Crohn's disease (CD) and ulcerative colitis (UC), has emerged as global disease, that affects over 2 million individuals in North America, 3.2 million in Europe, and millions more worldwide [54]. Collectively, these conditions can lead to a significant disability with a high impact on patients' quality of life. Accordingly, this recent global burden of IBD will require research to better detect early stages of IBD from preclinical symptoms and offer possibilities for disease prevention in high-risk individuals and prevent complications [55].

Multiple factors such as diet, gut barrier, microbiome, and activation of the innate and adaptive mucosal immune systems in genetically predisposed individuals are involved in the pathogenesis of IBD [56]. Microbiome imbalance seems to play a crucial role since significant changes in bacterial, viral, protist, and fungal populations have been observed in the gut microbiota of affected individuals [57].

In this context, probiotics become an attractive new option for treating IBD patients by reducing inflammation through the modulation of microbiota composition, improving and restoring epithelial and mucosal barrier function, and promoting an immunomodulatory effect
[58]. However, there is still limited evidence supporting their use in daily clinical practice to manage IBD.

Most studies had several limitations, including a wide variability in the composition and dosing of the probiotic preparation, small sizes of the study population, and confounding factors such as concomitant medications and diet. Since the IBD subtype, localisation, extension, and microbiota can differ between patients, it is not surprising that responses to probiotics should also vary.

Several trials evaluated the effect of probiotics in inducing and maintaining remission in $\mathrm{CD}$ and UC. Of note, many microorganisms, nonpathogenic bacteria and fungi, or combinations of them have been tested; however, consistent results have been obtained only with some of them, including Escherichia coli Nissle 1917, VSL\#3, Saccharomyces boulardii, Lactobacillus, and Bifidobacterium [59-63]. To date, the most robust evidence supporting the use of probiotics concerned the VSL\#3 that contains 8 strains of lactic acid-producing bacteria (Lactobacillus plantarum, Lactobacillus delbrueckii subsp. bulgaricus, Lactobacillus casei, Lactobacillus acidophilus, Bifidobacterium breve, Bifidobacterium longum, Bifidobacterium infantis, and Streptococcus salivarius subsp. thermophilus) [61].

A double-blind placebo-controlled trial, including 40 UC patients in remission showed that VSL\#3 effectively prevented clinical relapses compared to placebo. Indeed only $15 \%$ of the patients who received the probiotics relapsed within 9 months versus $100 \%$ of the placebo group [64].

Furthermore, VSL\#3 was effective in both primary prevention of pouchitis after ileal pouch anal anastomosis and maintenance of remission in UC patients $(\mathrm{RR}=1.67$, 95\% CI: $1.06-2.63, p=0.03$ ) and in avoiding UC relapses $(\mathrm{RR}=0.29,95 \% \mathrm{CI}: 0.10-0.83, p=0.02)$ when compared 
Table 3. Guidelines on the role of probiotics in IBD

\begin{tabular}{|c|c|c|c|c|}
\hline Source & Year & Recommendations & $\begin{array}{l}\text { Strength of } \\
\text { recommendation }\end{array}$ & $\begin{array}{l}\text { Quality of } \\
\text { evidence }\end{array}$ \\
\hline $\begin{array}{l}\text { Third European evidence- } \\
\text { based consensus on diagnosis } \\
\text { and management of UC [67] }\end{array}$ & 2017 & E. coli Nissle 1917 is effective in inducing and maintaining remission in UC & N/A & $\mathrm{N} / \mathrm{A}$ \\
\hline \multirow{3}{*}{$\begin{array}{l}\text { AGA clinical practice } \\
\text { guidelines on the role of } \\
\text { probiotics in the management } \\
\text { of gastrointestinal disorders } \\
\text { [52] }\end{array}$} & \multirow[t]{3}{*}{2020} & $\begin{array}{l}\text { In adults and children with CD, we recommend the use of probiotics only in } \\
\text { the context of a clinical trial }\end{array}$ & $\begin{array}{l}\text { No } \\
\text { recommendations }\end{array}$ & $\begin{array}{l}\text { Knowledge } \\
\text { gap }\end{array}$ \\
\hline & & $\begin{array}{l}\text { In adults and children with UC, we recommend the use of probiotics only in } \\
\text { the context of a clinical trial }\end{array}$ & $\begin{array}{l}\text { No } \\
\text { recommendations }\end{array}$ & $\begin{array}{l}\text { Knowledge } \\
\text { gap }\end{array}$ \\
\hline & & $\begin{array}{l}\text { In adults and children with pouchitis, we suggest the } 8 \text {-strain combination of } \\
\text { L. paracasei subsp paracasei, L. plantarum, L. acidophilus, L. delbrueckii subsp } \\
\text { bulgaricus, B longum subsp longum, B. breve, B. longum subsp infantis, and } \\
\text { S. salivarius subsp thermophilus over no or other probiotics }\end{array}$ & Conditional & Very low \\
\hline
\end{tabular}

IBD, inflammatory bowel disease; UC, ulcerative colitis; CD, Crohn's disease; AGA, American Gastroenterology Association.

to placebo [65]. Encouraging results came from a doubleblind trial that evaluated the efficacy of the Escherichia coli Nissle 1917 in maintaining UC remission. This study showed equivalence between this probiotic and mesalazine in preventing disease relapses, whose rates were $11.3 \%$ in the mesalazine group and $16.0 \%$ in the probiotics group, with a relapse-free time of $103 \pm 4$ days versus $106 \pm 5$ days, respectively [60].

Subsequently, a meta-analysis confirmed these results and concluded that Escherichia coli Nissle 1917 induced remission in $61.6 \%$ of patients, while that rate was $69.5 \%$ with mesalazine [66]. Notably, the current European Crohn's and Colitis Organisation (ECCO) guidelines considered Escherichia coli Nissle 1917 as effective in inducing and maintaining remission in UC (Table 3) [67].

Recently, several probiotics formulations are being tested. Interestingly, a double-blind study found that Bifidobacterium breve strain Yakult fermented milk did not affect maintaining of remission in UC patients [62]. Conversely, a randomised, placebo-controlled, double-blinded trial showed that Bifidobacterium longum 536 strain promoted a reduction in UC Disease Activity Index (UCDAI) after 8 weeks of treatment $(3.8 \pm 0.4$ at baseline vs. $2.6 \pm 0.4$ at week $8, p<0.01$ ), while no significant improvement in the UCDAI was observed among patients who received placebo $(4.5 \pm 0.5$ at baseline vs. $3.2 \pm 0.6$ at week $8, p=0.88$ ) [68]. A combination of Lactobacillus acidophilus La-5 and Bifidobacterium BB-12 impacts on intestinal parameters of affected individuals by increasing the prevalence of probiotic bacteria in the intestine and colon [69].

The fungus Saccharomyces boulardii, a yeast with antiinflammatory activity, has also been evaluated to prevent relapses in CD patients and remission of UC [59, 70, 71]. A randomised nonblinded study including $32 \mathrm{CD}$ patients showed that the clinical relapse rates within 6 months were found in the Saccharomyces boulardii plus mesalazine group (6.25\%) were lower than those observed in patients who used mesalazine alone (37.5\%) [72, 73].

However, there is still little evidence on the effectiveness of probiotics in $\mathrm{CD}$. A recent meta-analysis on the efficacy of probiotics for the induction of remission in CD showed an RR of failure to achieve a remission of 0.90 $(95 \% \mathrm{CI}=0.77-1.06)$ in the probiotics group versus the placebo group [74]. Similarly, according to Shen et al. [75], probiotics did not significantly benefit the subgroup of CD patients $(p=0.35, \mathrm{RR}=0.89)$.

Fedorak et al. [63] found significant effects of using probiotics for the remission of $\mathrm{CD}$ disease only when treatment exceeded 90 days compared to placebo at day $90(p<0.05)$. However, they did not find any significant differences in the rates of endoscopic recurrence [63].

In conclusion, the role of probiotics in the management of IBD is still being explored. To date, VSL\#3 might be recommended for the treatment of pouchitis, while Escherichia coli Nissle 1917 is used for inducing and maintaining remission in UC (Table 3) [67]. However, there is no solid evidence supporting the efficacy of probiotics in the treatment of active $\mathrm{CD}$, and data regarding their benefit in maintenance of remission are limited. Currently, the AGA guidelines recommend the use of probiotics in IBD only in the context of clinical trials or in treatment of pouchitis (Table 3) [52]. 


\section{Conclusions and Perspectives}

Over the years, it has become apparent that the gut microbiota is not a bystander in the complex biological events regulating intestinal homoeostasis, but it can contribute to digestive and extra-digestive diseases. With the emergence of these observations, interest in probiotics to modulate microbiota composition has increased worldwide in both community and healthcare settings. As a consequence, the probiotic market has grown rapidly and is predicted to expand exponentially. However, despite their widespread use, there are still many criticisms that deserve further discussion.

First of all, much of our knowledge on probiotic mechanisms is based on research using in vitro, animal, cell culture, or ex vivo human models, findings of which do not prove their clinical efficacy in vivo and cannot be easily translated to humans. Nevertheless, even when proven in clinical studies, the effectiveness of a probiotic strain can be generalised to other strains or other medical conditions.

Moreover, the results of published studies are conflicting for most probiotic strains and formulations, and even meta-analyses that are a comprehensive summary of studies addressing the same topic can just provide a general trend. Indeed, the heterogeneity of the included studies, mainly in terms of probiotic strain, formulation, dose and duration, and measured outcomes, may lead to overor misinterpretation of data. Additionally, although this does not necessarily compromise their reliability, many probiotic studies are funded by the same industries that produce probiotics.

Finally, most probiotics have been marketed as dietary supplements, rather than pharmaceutical products, eluding clinical use approval from medical regulatory agencies. Thus, the current regulation of probiotics is mostly inadequate to safeguard consumers and doctors, especially when dealing with the management of severe conditions. Although probiotics are generally regarded as safe, there are significant health concerns in specific populations such as young infants and neonates with very low birth weight, critically ill patients in intensive care units, and immunocompromised patients, in whom probiotics may be responsible for bacteraemia and fungaemia. On the other hand, most published clinical trials of probiotics do not provide enough information on the safety profile of probiotics.

Based on these premises, it is not surprising that the recently published "AGA Clinical Practice Guidelines on the Role of Probiotics in the Management of Gastrointes- tinal Disorders" failed to provide strong recommendations for the majority of the analysed indications [52]. Likewise, the evidence we reviewed here regarding the use of probiotics in $H$. pylori infection, IBS, and IBD is relevant and promising for probiotics in general, and for specific strains and combinations of strains, but not yet sufficient to draw unequivocal conclusions. Future rigorously designed, large-scale, randomised and blinded clinical trials tailoring probiotics to conditions and individuals with objectively assessed endpoints and aimed at defining the safety profile, preferentially devoid of commercial interests, together with more specific and stringent regulatory rules for probiotics, will allow filling the gap in the evidence needed to recommend probiotics in clinical practice. As the famous Spanish painter Pablo Picasso, one of the greatest artists of the 20th century, used to say "Do not judge wrong what you don't know, seize the opportunity to understand."

\section{Conflict of Interest Statement}

Gerardo Nardone has served as a speaker and advisory board member for AG Pharma, Reckitt Benckiser, and has received research funding from SOFAR Spa and Alfasigma.

\section{Funding Sources}

This study was not funded. The writing or preparation of this paper was not funded.

\section{Author Contributions}

D.C., C.S., O.M.N., and G.N. substantially contributed to the conception and design of the article; A.R., P.C., and C.L. contributed to review and interpret the relevant literature; D.C. and G.N. drafted the article or revised it critically for important intellectual content. All authors approved the final version of the manuscript.

References

1 Rijkers GT, de Vos WM, Brummer RJ, Morelli L, Corthier G, Marteau P. Health benefits and health claims of probiotics: bridging science and marketing. Br J Nutr. 2011;106(9): 1291-6.

2 Lynch SV, Pedersen O. The human intestinal microbiome in health and disease. N Engl J Med. 2016;375(24):2369-79.

3 Kataoka K. The intestinal microbiota and its role in human health and disease. J Med Invest. 2016;63(1-2):27-37.

4 Cani PD. Gut microbiota - at the intersection of everything? Nat Rev Gastroenterol Hepatol. 2017;14(6):321-2. 
5 Aziz Q, Doré J, Emmanuel A, Guarner F, Quigley EM. Gut microbiota and gastrointestinal health: current concepts and future directions. Neurogastroenterol Motil. 2013; 25(1):4-15.

6 Guinane CM, Cotter PD. Role of the gut microbiota in health and chronic gastrointestinal disease: Understanding a hidden metabolic organ. Therap Adv Gastroenterol. 2013;6(4):295-308.

7 Schmidt TSB, Raes J, Bork P. The human gut microbiome: from association to modulation. Cell. 2018;172(6):1198-215.

8 Parker EA, Roy T, D'Adamo CR, Wieland LS. Probiotics and gastrointestinal conditions: an overview of evidence from the cochrane collaboration. Nutrition. 2018;45:125-e11.

9 Suez J, Zmora N, Segal E, Elinav E. The pros, cons, and many unknowns of probiotics. Nat Med. 2019;25(5):716-29.

10 Preidis GA, Hill C, Guerrant RL, Ramakrishna BS, Tannock GW, Versalovic J. Probiotics, enteric and diarrheal diseases, and global health. Gastroenterology. 2011;140(1):8-14.

11 Koretz RL. Probiotics in gastroenterology: how pro is the evidence in adults? Am J Gastroenterol. 2018;113(8):1125-36.

12 Crowe SE. Helicobacter pylori Infection. N Engl J Med. 2019;380(12):1158-65.

13 Malfertheiner P, Link A, Selgrad M. Helicobacter pylori: perspectives and time trends. Nat Rev Gastroenterol Hepatol. 2014;11(10): 628-38.

14 Malfertheiner P, Megraud F, O'Morain CA, Gisbert JP, Kuipers EJ, Axon AT, et al. Management of helicobacter pylori infection-the Maastricht V/Florence consensus report. Gut. 2017;66(1):6-30.

15 Chey WD, Leontiadis GI, Howden CW, Moss SF. ACG clinical guideline: treatment of helicobacter pylori infection. Am J Gastroenterol. 2017;112(2):212-39.

16 Fallone CA, Chiba N, van Zanten SV, Fischbach L, Gisbert JP, Hunt RH, et al. The Toronto consensus for the treatment of helicobacter pylori infection in adults. Gastroenterology. 2016;151(1):51-e14

17 Fock KM, Katelaris P, Sugano K, Ang TL, Hunt R, Talley NJ, et al. Second Asia-Pacific consensus guidelines for helicobacter pylori infection. J Gastroenterol Hepatol. 2009; 24(10):1587-600

18 Thung I, Aramin H, Vavinskaya V, Gupta S, Park JY, Crowe SE, et al. Review article: the global emergence of helicobacter pylori antibiotic resistance. Aliment Pharmacol Ther. 2016;43(4):514-33.

19 Francavilla R, Lionetti E, Castellaneta SP, Magistà AM, Maurogiovanni G, Bucci N, et al. Inhibition of helicobacter pylori infection in humans by lactobacillus reuteri ATCC 55730 and effect on eradication therapy: a pilot study. Helicobacter. 2008;13(2):127-34.

20 Sakarya S, Gunay N. Saccharomyces boulardii expresses neuraminidase activity selective for a2,3-linked sialic acid that decreases helicobacter pylori adhesion to host cells. APMIS. 2014;122(10):941-50.
21 Chenoll E, Casinos B, Bataller E, Astals P, Echevarría J, Iglesias JR, et al. Novel probiotic bifidobacterium bifidum CECT 7366 strain active against the pathogenic bacterium helicobacter pylori. Appl Environ Microbiol. 2011;77(4):1335-43.

22 Pinchuk IV, Bressollier P, Verneuil B, Fenet $\mathrm{B}$, Sorokulova IB, Mégraud $\mathrm{F}$, et al. In vitro anti-helicobacter pylori activity of the probiotic strain bacillus subtilis 3 is due to secretion of antibiotics. Antimicrob Agents Chemother. 2001;45(11):3156-61.

23 Chen L, Xu W, Lee A, He J, Huang B, Zheng $\mathrm{W}$, et al. The impact of helicobacter pylori infection, eradication therapy and probiotic supplementation on gut microenvironment homeostasis: an open-label, randomised clinical trial. EBioMedicine. 2018;35:87-96.

24 Kang JH, Lee MS. In vitro inhibition of helicobacter pylori by enterococcus faecium GM1. Can J Microbiol. 2005;51(8):629-36.

25 Kabir AM, Aiba Y, Takagi A, Kamiya S, Miwa T, Koga Y. Prevention of helicobacter pylori infection by lactobacilli in a gnotobiotic murine model. Gut. 1997;41(1):49-55.

26 Homan M, Orel R. Are probiotics useful in helicobacter pylori eradication? World J Gastroenterol. 2015;21(37):10644-53.

27 Song H, Zhou L, Liu D, Ge L, Li Y. Probiotic effect on helicobacter pylori attachment and inhibition of inflammation in human gastric epithelial cells. Exp Ther Med. 2019;18(3): 1551-62.

28 Losurdo G, Cubisino R, Barone M, Principi $M$, Leandro $G$, Ierardi E, et al. Probiotic monotherapy and Helicobacter pylori eradication: a systematic review with pooled-data analysis. World J Gastroenterol. 2018;24(1): $139-49$.

29 Lu M, Yu S, Deng J, Yan Q, Yang C, Xia G, et al. Efficacy of probiotic supplementation therapy for helicobacter pylori eradication: a meta-analysis of randomized controlled trials. PLoS One. 2016;11:e0163743.

30 Yu M, Zhang R, Ni P, Chen S, Duan G. Efficacy of lactobacillus-supplemented triple therapy for $\mathrm{H}$. pylori eradication: a metaanalysis of randomised controlled trials. PLoS One. 2019;14:e0223309.

31 Zhang M, Zhang C, Zhao J, Zhang H, Zhai Q, Chen W. Meta-analysis of the efficacy of probiotic-supplemented therapy on the eradication of $\mathrm{H}$. pylori and incidence of therapy-associated side effects. Microb Pathog. 2020; 147:104403.

32 Black CJ, Ford AC. Global burden of irritable bowel syndrome: trends, predictions and risk factors. Nat Rev Gastroenterol Hepatol. 2020; 17(8):473-86.

33 Lacy BE, Mearin F, Chang L, Chey WD, Lembo AJ, Simren M, et al. Bowel disorders. Gastroenterology. 2016;150:1393-407.

34 Ford AC, Moayyedi P, Chey WD, Harris LA, Lacy BE, Saito YA, et al. American college of gastroenterology monograph on management of irritable bowel syndrome. Am J Gastroenterol. 2018;113:1-18.
35 Bellini M, Gambaccini D, Stasi C, Urbano MT, Marchi S, Usai-Satta P. Irritable bowel syndrome: a disease still searching for pathogenesis, diagnosis and therapy. World J Gastroenterol. 2014;20(27):8807-20.

36 Marshall JK, Thabane M, Borgaonkar MR, James C. Postinfectious irritable bowel syndrome after a food-borne outbreak of acute gastroenteritis attributed to a viral pathogen. Clin Gastroenterol Hepatol. 2007;5(4):45760.

37 Pimentel M, Chow EJ, Lin HC. Normalization of lactulose breath testing correlates with symptom improvement in irritable bowel syndrome. a double-blind, randomized, placebo-controlled study. Am J Gastroenterol. 2003;98(2):412-9.

38 Pimentel M, Lembo A, Chey WD, Zakko S, Ringel Y, Yu J, et al. Rifaximin therapy for patients with irritable bowel syndrome without constipation. N Engl J Med. 2011;364(1):2232.

39 Yang J, Lee HR, Low K, Chatterjee S, Pimentel M. Rifaximin versus other antibiotics in the primary treatment and retreatment of bacterial overgrowth in IBS. Dig Dis Sci. 2008; 53(1):169-74.

40 Quigley EM. Gut microbiota and the role of probiotics in therapy. Curr Opin Pharmacol. 2011;11(6):593-603.

41 Plaza-Diaz J, Ruiz-Ojeda FJ, Gil-Campos M, Gil A. Mechanisms of action of probiotics. Adv Nutr. 2019;10(Suppl 1 1):S49-66.

42 Delforge M, Maupas JL, Champemont P. Traitement des colopathies fonctionelles: essai en double aveugle du perenterol ${ }^{\circ}$. Rev Med Liege. 1983;38:885-8.

43 Brenner DM, Moeller MJ, Chey WD, Schoenfeld PS. The utility of probiotics in the treatment of irritable bowel syndrome: a systematic review. Am J Gastroenterol. 2009;104(4): 1033-50.

44 Ford AC, Harris LA, Lacy BE, Quigley EMM, Moayyedi P. Systematic review with metaanalysis: the efficacy of prebiotics, probiotics, synbiotics and antibiotics in irritable bowel syndrome. Aliment Pharmacol Ther. 2018; 48(10):1044-60.

45 Niu H-L, Xiao J-Y. The efficacy and safety of probiotics in patients with irritable bowel syndrome: evidence based on 35 randomised controlled trials. Int J Surg. 2020;75:116-27.

46 Preidis GA, Weizman AV, Kashyap PC, Morgan RL. AGA technical review on the role of probiotics in the management of gastrointestinal disorders. Gastroenterology. 2020; 159(2):708-e4.

47 Andresen V, Gschossmann J, Layer P. Heatinactivated bifidobacterium bifidum MIMBb75 (SYN-HI-001) in the treatment of irritable bowel syndrome: a multicentre, randomised, double-blind, placebo-controlled clinical trial. Lancet Gastroenterol Hepatol. 2020;5(7):658-66.

48 Adams CA. The probiotic paradox: live and dead cells are biological response modifiers. Nutr Res Rev. 2010;23(1):37-46. 
49 Martoni CJ, Srivastava S, Leyer GJ. Lactobacillus acidophilus DDS-1 and bifidobacterium lactis UABla-12 improve abdominal pain severity and symptomology in irritable bowel syndrome: randomized controlled trial. $\mathrm{Nu}-$ trients. 2020;12(2):363.

50 Gayathri R, Aruna T, Malar S, Shilpa B, Dhanasekar KR. Efficacy of saccharomyces cerevisiae CNCM I-3856 as an add-on therapy for irritable bowel syndrome. Int J Colorectal Dis. 2020;35(1):139-45.

51 Madempudi RS, Ahire JJ, Neelamraju J, Tripathi A, Nanal S. Randomized clinical trial: the effect of probiotic Bacillus coagulans unique IS2 versus placebo on the symptoms management of irritable bowel syndrome in adults. Sci Rep. 2019;9(1):12210.

52 Su GL, Ko CW, Bercik P, Falck-Ytter Y, Sultan $\mathrm{S}$, Weizman AV, et al. AGA clinical practice guidelines on the role of probiotics in the management of gastrointestinal disorders. Gastroenterology. 2020;159(2):697-705.

53 Lacy BE, Pimentel M, Brenner DM, Chey WD, Keefer LA, Long MD, et al. ACG clinical guideline: management of irritable bowel syndrome. Am J Gastroenterol. 2021 Jan; 116(1):17-44.

54 Alatab S, Sepanlou SG, Ikuta K, Vahedi H, Bisignano C, Safiri S, et al. The global, regional, and national burden of inflammatory bowel disease in 195 countries and territories, 1990 2017: a systematic analysis for the global burden of disease study 2017. Lancet Gastroenterol Hepatol. 2020;5:17-30.

55 Jairath V, Feagan BG. Global burden of inflammatory bowel disease. Lancet Gastroenterol Hepatol. 2020;5(1):2-3.

56 Xavier RJ, Podolsky DK. Unravelling the pathogenesis of inflammatory bowel disease. Nature. 2007;448(7152):427-34.

57 Loftus EV. Clinical epidemiology of inflammatory bowel disease: incidence, prevalence, and environmental influences. Gastroenterology. 2004;126(6):1504-17.

58 Silva NO, Brito BB, Silva FAF, Santos MLC, Melo FF. Probiotics in inflammatory bowel disease: oes it work? World J Meta-Analysis. 2020;8:54-66.
59 Dalmasso G, Cottrez F, Imbert V, Lagadec P, Peyron JF, Rampal P, et al. Saccharomyces boulardii inhibits inflammatory bowel disease by trapping $\mathrm{T}$ cells in mesenteric lymph nodes. Gastroenterology. 2006;131(6):181225.

60 Kruis W, Schütz E, Fric P, Fixa B, Judmaier G, Stolte M. Double-blind comparison of an oral Escherichia coli preparation and mesalazine in maintaining remission of ulcerative colitis. Aliment Pharmacol Ther. 1997;11(5):853-8.

61 Mora D, Filardi R, Arioli S, Boeren S, Aalvink S, de Vos WM. Development of omics-based protocols for the microbiological characterisation of multistrain formulations marketed as probiotics: the case of VSL\#3. Microb Biotechnol. 2019;12:1371-86.

62 Matsuoka K, Uemura Y, Kanai T, Kunisaki R, Suzuki Y, Yokoyama K, et al. Efficacy of bifidobacterium breve fermented milk in maintaining remission of ulcerative colitis. Dig Dis Sci. 2018;63(7):1910-9.

63 Fedorak RN, Feagan BG, Hotte N, Leddin D, Dieleman LA, Petrunia DM, et al. The probiotic vsl\#3 has anti-inflammatory effects and could reduce endoscopic recurrence after surgery for crohn's disease. Clin Gastroenterol Hepatol. 2015;13(5):928-e2.

64 Gionchetti P, Rizzello F, Venturi A, Brigidi P, Matteuzzi D, Bazzocchi G, et al. Oral bacteriotherapy as maintenance treatment in patients with chronic pouchitis: a double-blind, placebo-controlled trial. Gastroenterology. 2000; 119(2):305-9.

65 Jia K, Tong X, Wang R, Song X. The clinical effects of probiotics for inflammatory bowel disease: a meta-analysis. Medicine. 2018; 97(51):e13792.

66 Losurdo G, Iannone A, Contaldo A, Ierardi E, Di Leo A, Principi M. Escherichia coli Nissle 1917 in ulcerative colitis treatment: systematic review and meta-analysis. J Gastrointestin Liver Dis. 2015;24(4):499-505.
67 Harbord M, Eliakim R, Bettenworth D, Karmiris K, Katsanos K, Kopylov U, et al. Third european evidence-based consensus on diagnosis and management of ulcerative colitis. Part 2: current management. J Crohns Colitis. 2017 Jul;11(7):769-84

68 Tamaki H, Nakase H, Inoue S, Kawanami C, Itani $\mathrm{T}$, Ohana $\mathrm{M}$, et al. Efficacy of probiotic treatment with Bifidobacterium longum 536 for induction of remission in active ulcerative colitis: a randomised, double blinded, placebo controlled multicenter trial. Dig Endosc. 2016;28:67-74.

69 Shadnoush M, Hosseini RS, Khalilnezhad A, Navai L, Goudarzi H, Vaezjalali M. Effects of probiotics on gut microbiota in patients with inflammatory bowel disease: a double-blind, placebo-controlled clinical trial. Korean J Gastroenterol. 2015;65(4):215-21.

70 Guslandi M, Mezzi G, Sorghi M, Testoni PA. Saccharomyces boulardii in maintenance treatment of Crohn's disease. Dig Dis Sci. 2000;45(7):1462-4.

71 Guslandi M, Giollo P, Testoni PA. A pilot trial of Saccharomyces boulardii in ulcerative colitis. Eur J Gastroenterol Hepatol. 2003; 15(6):697-8.

72 Guslandi M, Mezzi G, Sorghi M, Testoni PA. Saccharomyces boulardii in maintenance treatment of Crohn's disease. Dig Dis Sci. 2000;45(7):1462-4.

73 Bourreille A, Cadiot G, Le Dreau G, Laharie D, Beaugerie L, Dupas JL, et al. Saccharomyces boulardii does not prevent relapse of Crohn's disease. Clin Gastroenterol Hepatol. 2013;11(8):982-7.

74 Pabón-Carrasco M, Ramirez-Baena L, VilarPalomo S, Castro-Méndez A, Martos-García R, Rodríguez-Gallego I. Probiotics as a coadjuvant factor in active or quiescent inflammatory bowel disease of adults-a meta-analytical study. Nutrients. 2020;12:1-17.

75 Shen J, Zuo ZX, Mao AP. Effect of probiotics on inducing remission and maintaining therapy in ulcerative colitis, Crohn's disease, and pouchitis: meta-analysis of randomised controlled trials. Inflamm Bowel Dis. 2014;20 21-35. 